\title{
Evaluation of Art Research for Sustainable Development
}

\author{
LESLEY BROOK
}

\begin{abstract}
An exhibition of environmental artworks in 2020 created value for members of the public. The artists were responding to climate change and wider issues of humancaused changes to the planet. This study, undertaken for the researcher's Master of Professional Practice, evaluated the emotional impact of that exhibition on visitors. Each participant sorted photographs of the artworks according to the strength of their positive/negative emotional responses to the artworks. This was followed by a semi-structured interview. This paper presents the results of analysis of the transcripts of answers by 24 participants to three of the questions asked in interview. Participants were asked to describe how they feel about the effects of human activity on our world, to identify which artwork or artworks most closely represented how they felt about that, and whether they thought or felt differently about the effects of human activity on our world after experiencing this exhibition. Their answers suggest that a values-driven approach is suitable for improving human and institutional capacity on climate change mitigation, and that environmental art has a valuable role to play, to maintain awareness about climate action and to encourage public support for environmental initiatives.
\end{abstract}

KEYWORDS: Environmental artworks; Emotional impact; Anthropocene; Effects of human activity; Feelings.

Art plays an important role in engaging people, because it "activates emotions, memories, learning and meaning-making in the brain in unique and complex ways," and hence art can encourage viewers to "reconsider issues of planetary change with new urgency" (Hudson Hill, 2020, p. 79). To this end, an art exhibition on the theme of the Anthropocene, all the different and cumulative effects that human activities have been having on the environment, was held at the Dunedin School of Art at Otago Polytechnic in Dunedin, New Zealand. The exhibition was called The Complete Entanglement of Everything, recognising the complex web of connections between people and the environments in which we live.

\section{Value Creation}

The exhibition was open to the public for one week from Saturday 26 September to Friday 2 October 2020. There were more than 60 contemporary environmental artworks in the exhibition, by 48 artists. Painting, print-making, fabric works, sculpture, video and sound works were 
all represented (Lonie, 2020). Experiencing the exhibition gave audiences "space and time to negotiate what we feel" about climate change and wider issues of human-caused changes to the planet (Lonie, 2020). As well as providing this opportunity to make sense of thoughts and feelings, the curator's hope for the exhibition was to increase people's feelings of connectedness with the environment and with each other (B. Lonie, personal communication, 10 March 2020).

The prevailing view of the environment is still economic, treating it as a resource to be used for human advantage, but this view is being challenged. Leopold advocated for a land ethic that limits humanity's freedom of action, seeing ourselves as citizens of an ecological community and recovering a sense of relationship with land (Leopold, 1987). Bouma-Prediger has proposed that a set of ecological virtues is needed to shape character and hence influence behaviour: respect and receptivity; self-restraint and frugality; humility and honesty; wisdom and hope; patience and serenity; benevolence and love; and justice and courage (Bouma-Prediger, 2001). Sideris suggests that we should love our neighbour in "the whole community of life", recognizing that the value of any organism lies in its criticality in its ecosystem (Sideris, 2006, p. 447). Our attitude towards the environment and how we value it, are instrumental in our behavior towards it.

Curtis, Reid and Reeve developed a model from their research that identifies three pathways by which art can influence environmental behaviour: communicating information, creating empathy for the natural environment, and embedding the arts in ecologically sustainable development (Curtis et al., 2014). Keller et al. add that emotional engagement includes place attachment and connection with the natural environment; making meaning helps to generate emotional engagement (Keller et al., 2020). According to Merrick, art can help overcome barriers to behavior change by creatively connecting viewers not just with the environment but also with each other and with new ways of seeing the issues. That study into the impact of an exhibition of environmental artworks confirmed that evoking an emotional response, for example a feeling of protectiveness, was one of the ways the exhibition engaged viewers (Merrick, 2011). In these ways environmental artworks can contribute to climate action and more sustainable cities and communities.

\section{Research Evaluation}

This paper is part of a study evaluating the emotional impact of that exhibition. The exhibition can be said to provide education for sustainable development to the public, and the evaluation provides education for sustainable development for the researcher and for the Dunedin School of Art. Ethics approval was obtained from the CapableNZ Ethics Committee at Otago Polytechnic, and 25 participants recruited from amongst visitors to the exhibition. The researcher met with all participants individually within two weeks of the exhibition closing, each of whom consented to participate. Each participant sorted 54 photographs of the artworks according to the strength of their positive/negative emotional responses to the artworks. Semi-structured interviews with each participant then were audio-recorded and transcribed.

\section{Analysis}

This paper presents the results of analysis of answers to three of the questions asked in interview. Participants were asked to describe how they felt about the effects of human activity on our world, and then to identify which artwork or artworks most closely represented how they 
felt about that. Thirdly, participants were asked whether they thought or felt differently about the effects of human activity on our world after experiencing this exhibition. Answers to the three questions were extracted from each transcript, together with any other comments which a participant may have made already in interview about the artwork/s which they selected in answer to the second question.

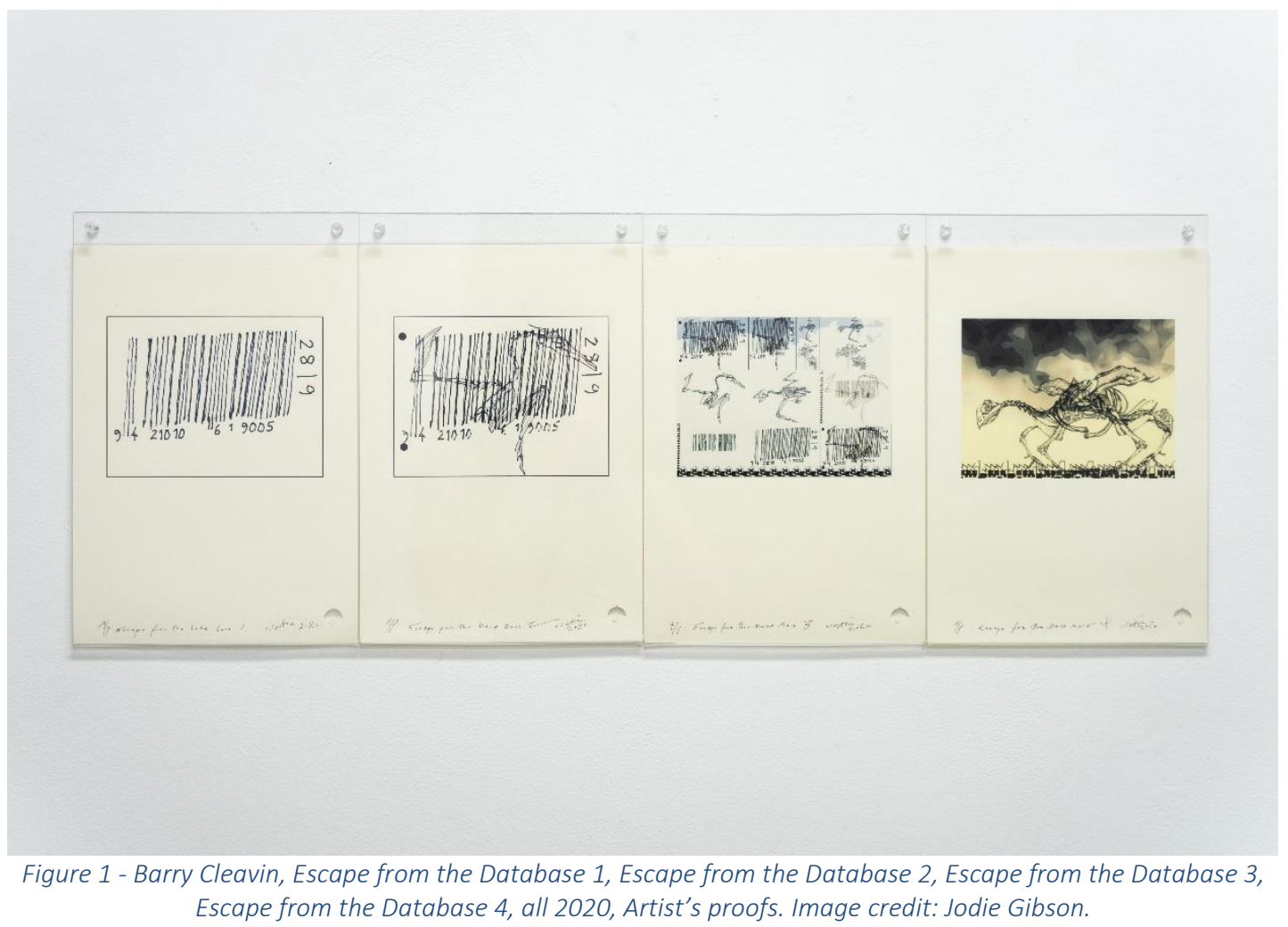

Analysis began with the answers to the first question from 24 participants who all had strong negative feelings about the effects of human activity on the environment. Some felt optimistic about the future or could see some good, some were very pessimistic, and the remainder fell in between these two views. The remaining participant was excluded from analysis as an outlier: this participant reported feeling positive about the effects of human activity on the world, and was the only one unable to identify an artwork which represented how they felt.

Although the question asked how they felt, participants described what they thought or knew as well as or instead of what they felt. Coding of the transcripts began with seven emergent themes as preliminary codes. This process identified additional potential codes and also similarities between some of the codes, generating four clusters or groups of comments in participants' answers: 1) what people think/know about Causes of environmental degradation; 2) what people think/know about Effects of human activity on the environment; 3) Feelings people have about this; and 4) behavioural Responses to make to this. The next step was to assign to one of these four groups all key words, phrases or comments in participants' responses to the first question. This was followed by sorting similar concepts within each group, revealing that Causes were either Behaviours or Attitudes/Values. In their answers to the first question about how they felt, 21 of the 24 participants made comments that fell into more than one of the four categories Causes, Effects, Feelings and Responses. 


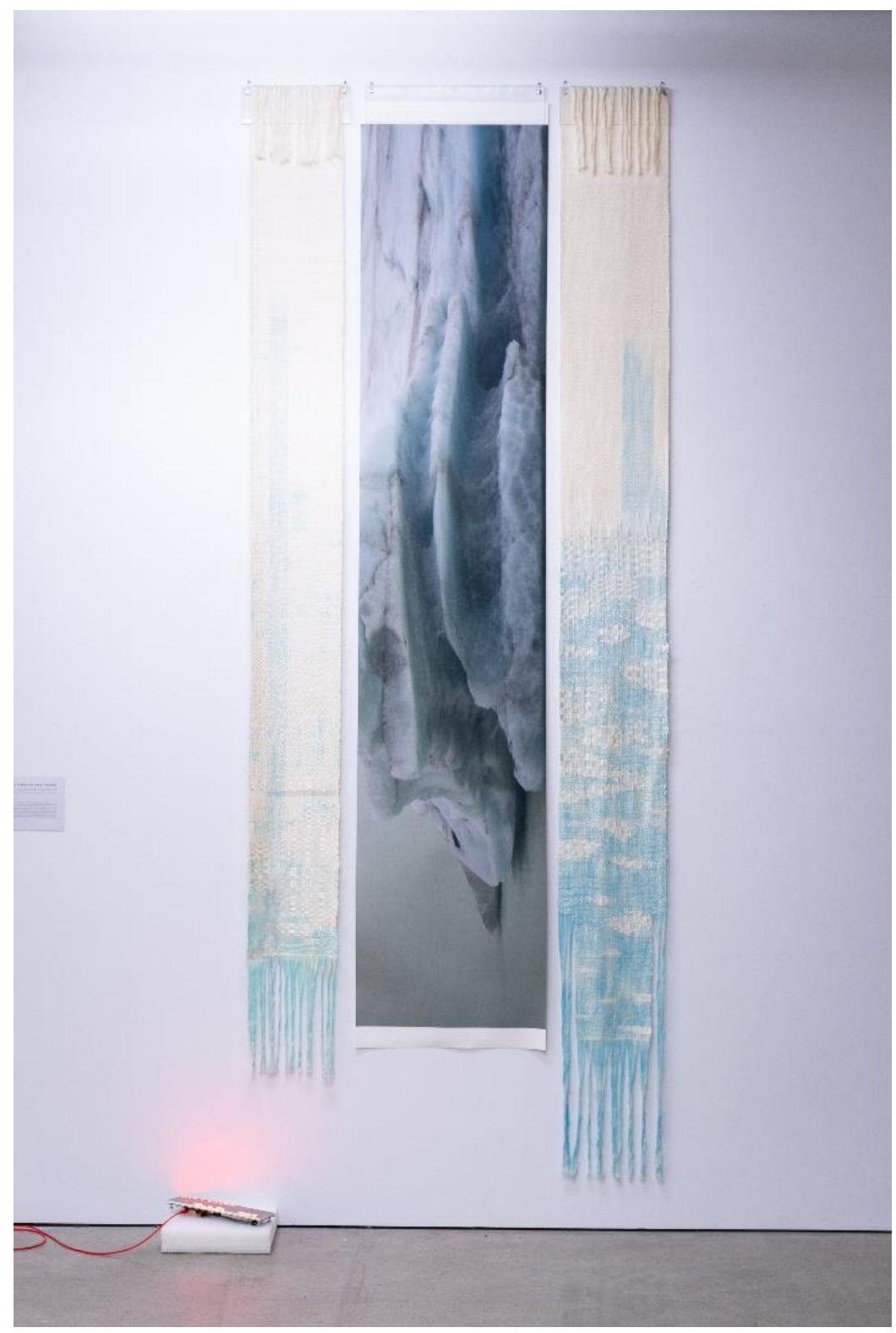

Figure 2 - Pam McKinlay and Henry Greenslade, Farewell - from the Tasman Glacier (from the "Ice is Cool" series), 2019, handwoven from fine wool khata (McKinlay), electronics (Greenslade). Image credit: Jodie Gibson.

The second question asked participants to select one or more artworks that most closely represented how they felt about the effects of human activity on our world. Their comments about the artwork/s they selected for the second question were able to be sorted into the same four groups, Causes, Effects, Feelings and Responses.

The third question asked if participants thought or felt differently about the effects of human activity on our world after experiencing this exhibition, and whether anything had changed for them. During interview transcription, three common responses emerged as preliminary codes. Detailed analysis confirmed these and identified additional, individual, answers. 


\section{Findings}

\section{Feelings about the effects of human activity on our world}

The behavioural Causes mentioned by participants were: out of control consumption; resource extraction; stockpiling waste; the industrial revolution; human animals being too successful; out of balance; being poor stewards; causing more damage when we try to fix things; and ignorance. But most of the Causes identified were Attitudes/Values: greed (mentioned by five participants); selfishness/self-interest (five); capitalism (four); our values/priorities (four); our lifestyle of conveniences; not being kind or caring; lost connection to land; the idea that the earth is at our disposal; expansion, exponential growth; economic growth; and being trapped in a system. While the causes identified by participants included behaviours, the negative effects of human behaviour on the world were attributed largely to systemic issues in human society and the underlying values or priorities. It also appears that how humans treat the environment is closely related to and may even be a corollary of human attitudes towards one another. How can we learn to love the environment in practice until we learn to love our human neighbour? "Who is my neighbour?" ${ }^{1}$ Not just the person physically next door but also the person who sewed the buttons on the shirt I wear and the person who lives downstream from the factory which dyed the fabric. These participant responses suggest that a valuesdriven approach is needed for improving human and institutional capacity for climate change mitigation. Such a values-driven approach to environmentalism shifts the discussion from considering what we ought to do, to ask what kind of people we ought to be.

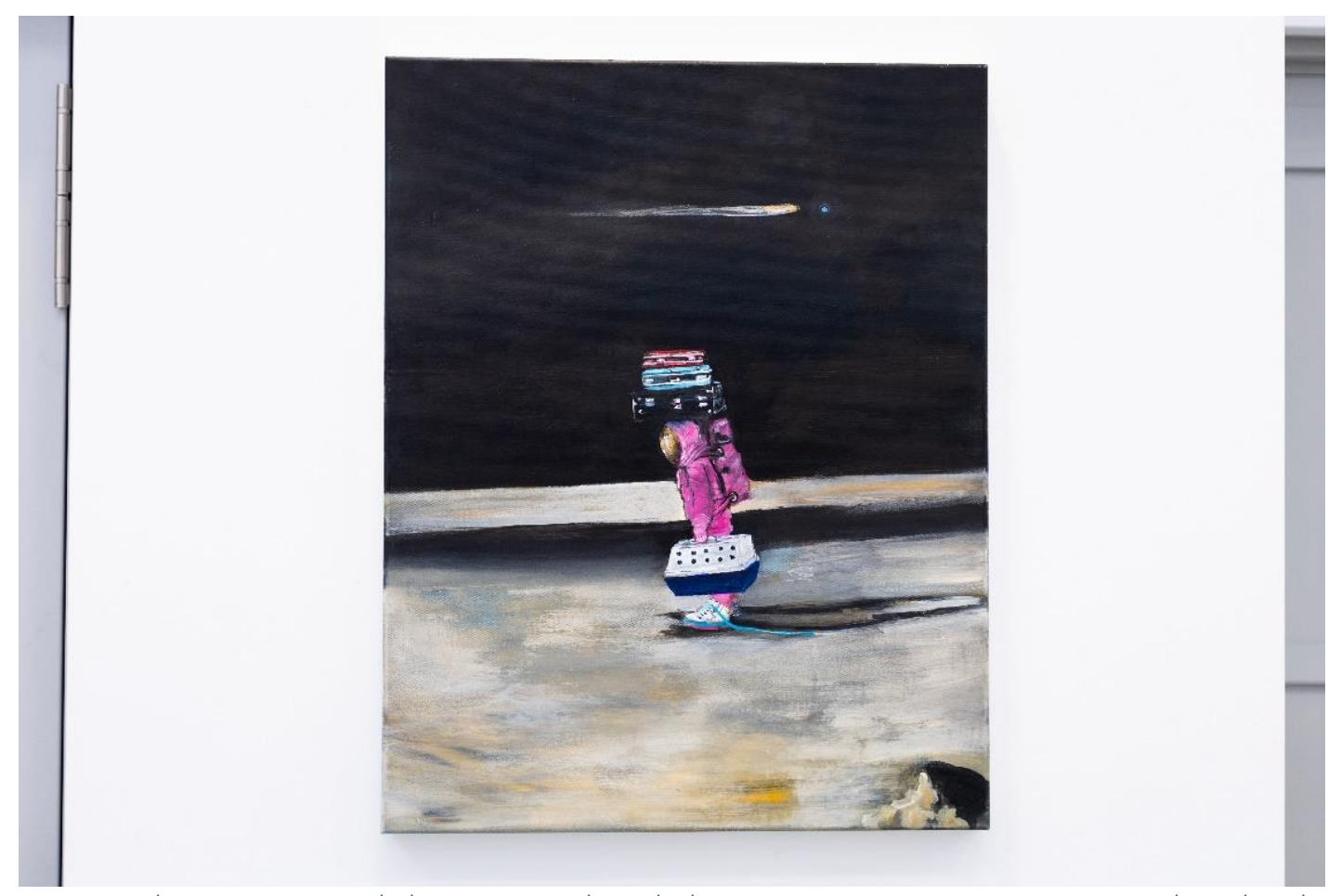

Figure 3 - Sharon Singer, Wanderlust, 2019, acrylic and oil on canvas, $710 \mathrm{~mm} \times 560 \mathrm{~mm}$. Image credit: Jodie Gibson. 
Amongst those who named Effects when explaining how they felt about the human activities on our world, some participants referred generally to future chaos or to the degradation and destruction already occurring, while others named specific effects: waste; depleted resources (overfishing, deforestation); mining for fossil fuels; and the subjugation and extinction of animals. Two participants explicitly linked humans' treatment of the environment with effects on other humans. One was concerned about the way we are leaving the world for the next generation. The other had no confidence that humans would change our environmental behaviours - "you've just got to look at all the torture and wars and murders and racism and all the things that humans do to each other let alone any other animals or environments". Although care for other humans has the potential to be a motivator for environmentally friendly behaviours, this could be difficult to engage successfully.

The Feelings named by participants related both to what has already been happening and also to the future. Words used to describe feelings about the present situation were: sadness (mentioned by eleven participants), anger, guilt, depressed, grief/bereft, shame, embarrassed, upsetting, distressed, troubled, disgusted, mortified, horrified and outrageous. Words used to describe feelings about the future were: scary, anxious, powerless/impotent/helpless, frustrated, urgency, overwhelmed, care/compassion, optimism and pessimism. The feelings were overwhelmingly negative, with only care/compassion and optimism representing a more hopeful perspective.

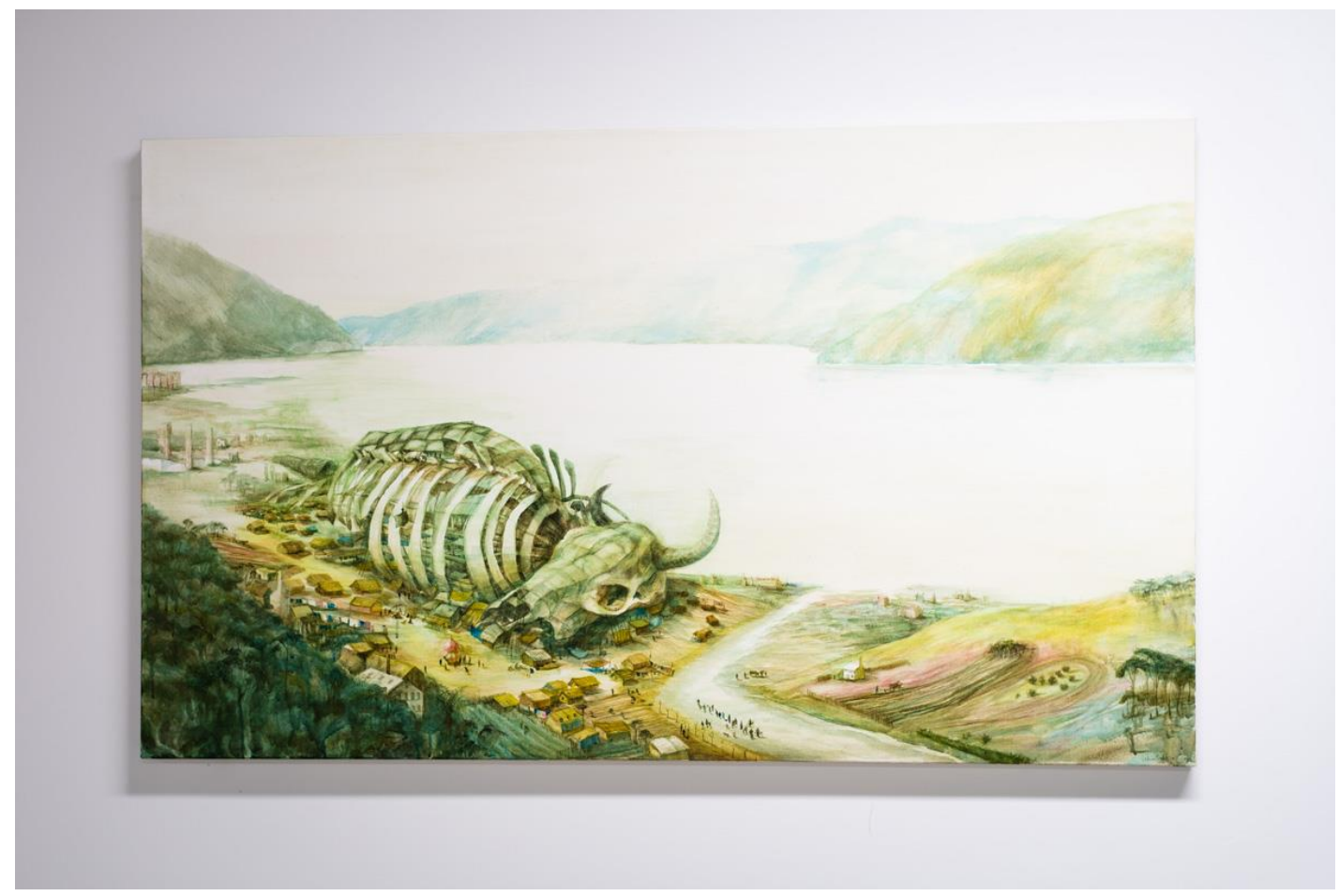

Figure 4 - Jenna Packer, Harbourside, acrylic on canvas. Image credit: Jodie Gibson.

The Responses which participants mentioned included both things they were already doing and things they thought should be done. While three participants referred generally to taking action personally, others named examples of their actions: using recyclable bags; being vegan; immersing self in nature; not having children; influencing others; practising sustainably (materials); paying attention to animals; member of the Green Party; and being involved in community action. There were also a wide range of actions which people suggested were needed: retain or regain skills; give up conveniences; care more; take responsibility; search out good 
things happening; hold people to account for using unsustainable or unethically sourced materials; reduce carbon footprint; address structural issues; more action by government/corporations; community action; collaborate; deal with poor environmental practices rurally; just "stop", turn the clock back; and use humour.

Three participants referred to humanity being at a tipping point or crossroads. While many of the actions specified by participants are personal, they also identified the need to act collectively as communities, corporates and countries. Joining community groups or political parties can be a way of contributing to change, but individual consumer behaviours also mattered to participants.

\section{Artworks that represented how participants felt about human activity}

Eleven participants selected one artwork that represented how they felt, ten selected two artworks, two selected three and one participant selected five artworks. Of the 13 people who chose more than one artwork, eight explained their choices using more than one of the four categories. Participants simultaneously held different thoughts and feelings about the effects of human activity on the environment, showing the complexity of the subject. The artworks were able to reflect the variety and complexity of thoughts and feelings.

\section{Whether participants thought or felt differently after the exhibition}

The third question asked of participants and covered by this paper was whether they thought or felt differently about the effects of human activity on our world after experiencing this exhibition. For seven participants there was no change in what they thought or felt. This was an unsurprising result given the strong views they already held, but two participants expressed disappointment that the exhibition had not achieved some change for them.

Six participants reported that the effect of the exhibition for them was reinforcement or strengthening of what they already thought and felt about the environment. For example, one participant said:

"I think I feel more in touch with it. ... [Y]ou do come to something like this and you just remember again ... what's actually at stake and you do have a really emotional response to that. And I guess it also helped in a way to remember how important these things actually are".

Six participants also felt encouraged that there was such a large community of local artists addressing environmental issues. As one expressed it:

\footnotetext{
"[W]ith each exhibition like this it does add a sliver of hope, where it's just good to know I'm not the only one if that makes sense, because there are definitely times when it feels like you're the lone voice crying out to the void, and cognitively you know there are others but it's different to know it and then it's different to feel it, and this is what allows you to feel that and actually get to see that others are trying to do the same thing".
}

For five participants the exhibition changed how they see every day and local things, or how they viewed art or artists. One person had been thinking about some of the artworks since the exhibition, while washing containers for recycling. The remaining four participants reported:

\footnotetext{
"since the exhibition I've definitely looked at a wider range of things just in my everyday life and 
kind of understood yes, that is very connected, very valid"

"it's maybe just reminded me of that, just stopping and paying attention to your local area that maybe isn't particularly dramatic ...., that there's value in that"

"they're connections that these artists have made with their environment, with the materials of their making and with me"

"something has changed I think and I think it is ... that the importance of making things, of artists creating and making work is now more important than ever"

The answers to this third question demonstrate that the exhibition succeeded in creating value for 17 of 24 participants (71\%). Environmental art has a valuable role to play, to maintain awareness about climate action and other environmental issues, and to encourage public engagement with environmental behaviours.

\section{Education for Sustainable Development}

This study was undertaken for my Master of Professional Practice degree at Otago Polytechnic. My field of professional practice is research management including the evaluation of research impact. I saw the exhibition myself but more significant for me than the exhibition was the interviews, conducted from 30 September to 16 October. Listening to 24 people express such intense negative feelings on environmental issues has affected me. I am privileged they chose to share their thoughts and feelings with me and I thank them. This experience was reinforced by hearing the participants' voices again during transcription. I gained a new sense of urgency about environmental issues that has challenged my sense of complacency.

One participant touched on this issue of education: "it's a hard balance between wanting to educate people but not wanting to sound patronising, and, but being really concerned about it". As reported above, some participants gained a stronger sense of being part of a community of sustainable practice with the many artists whose work was included in the exhibition, and I feel part of a community of sustainable practice with my research participants. I suggest that this should be an important part of education for sustainable development, the establishment and nurturing of such communities of sustainable practice, where individuals can inspire and encourage one another without being judgemental or patronising.

This study confirms that an exhibition of environmental art can play a role in encouraging public participation in environmental action. However, successfully addressing the causes of environmental degradation is likely to require attention to systemic issues and the underlying values and attitudes, not just to behaviour change.

\section{Literature}

Bouma-Prediger, S. (2001). What kind of people ought we be? Earth-care and character. In For the beauty of the earth: A Christian vision for creation care (pp. 131-154). Baker Academic. 
Curtis, D. J., Reid, N., \& Reeve, I. (2014). Towards ecological sustainability: Observations on the role of the arts. SAPIENS, 7(1). http://journals.openedition.org/sapiens/1655

Hudson Hill, S. (2020). A Terrible Beauty: Art and Learning in the Anthropocene. Journal of Museum Education, 45(1), 74-90. https://doi.org/10.1080/10598650.2020.1723357

Keller, A., Sommer, L., Klöckner, C. A., \& Hanss, D. (2020). Contextualizing Information Enhances the Experience of Environmental Art. Psychology of Aesthetics, Creativity, and the Arts, 14(3), 264-275. https://doi.org/10.1037/aca0000213

Leopold, A. (1987). The Land Ethic. In A Sand County almanac, and sketches here and there (pp. 201-226). Oxford University Press.

Lonie, B. (2020). In Dunedin School of Art, The Complete Entanglement of Everything exhibition catalogue. Otago Polytechnic. https://issuu.com/dunedinschoolofart/docs/the_complete_entanglement_of_everything_exhibition

Lonie, B. (2020, March 10). [Personal communication].

Merrick, K. (2011). The Power of Art to Engage the Public on the Impacts of Climate Change on the Coast. Curtin University.

Sideris, L. H. (2006). Religion, Environmentalism, and the Meaning of Ecology. In R. S. Gottlieb (Ed.), The Oxford Handbook of Religion and Ecology. Oxford University Press. 